\title{
Effect of Educational Interventions on Reducing Stress Urinary Incontinence Episodes among elderly Women
}

\author{
${ }^{1}$ Asmaa Emad Mohammed, ${ }^{2}$ Mohammed Salah Eldeen Mohamed, ${ }^{3}$ Sahar Hamza Taha, \\ ${ }^{4}$ Rakaia Fathi Mohammed
}

1. Clinical Instructor, Technical Institute of Nursing, Faculty of Nursing, Minia University, Egypt.

2. Professor of Urology, Faculty of Medicine, Minia University, Egypt.

3. Lecturer of Medical-Surgical Nursing, Faculty of Nursing, Minia University, Egypt.

4. Lecturer of Medical Surgical Nursing (geriatric Nursing), Faculty of Nursing, Minia University, Egypt.

*Email of the corresponding author: emannagi@mu.edu.eg

\begin{abstract}
Background: Stress urinary incontinence (SUI) is the most common urological problem among elderly women that negatively impacting the quality of their life. Aim of the study: Is to evaluate the effect of educational interventions on reducing stress urinary incontinence episodes among elderly women. Research design: Quasi- experimental research design was utilized. Subjects: A purposeful sample of (50) elderly women was selected. Setting: The study was conducted in Geriatric Nursing Home of Ministry of Social Solidarity and in Geriatric Club of The Red Crescent Society at Minia, Egypt. Tools of data collection: Two tools were utilized. First Tool: A Structured questionnaire sheet covered demographic characteristics and medical profile. Second Tool: Is Revised Urinary Incontinence Scale (RUIS).Results: The severity of stress urinary incontinence were declined after implementation of an educational intervention to $8 \%$ compared to $24 \%$ than before, with a highly statistically significant difference $(\mathrm{p}=.001)$. Additionally, there were highly statistically significant differences between (age, education, occupation, and place of residence) and the severity of (SUI). Conclusion: Applying an educational intervention was effective in reducing SUI episodes among elderly women. Recommendations: A continuous education and training should be offered on a regular basis for elderly women to reduce episodes of stress urinary incontinence.
\end{abstract}

Key Words: Behavioral therapy- Elderly women -Stress Urinary Incontinence

\section{Introduction}

Stress Urinary incontinence (SUI) considers the most common and distressing health problem among the aging population especially older women, associated with a profound negative impact on the quality of life. Its prevalence estimates 30 to $50 \%$ and increases with age among community-dwelling older adults and represents 50 to $60 \%$ among nursing home residents. Women are at more risk for SUI three times more than men, because of anatomic, social, and cultural status and also because of the effects of pregnancy, delivery, and menopause (National Association for Continence, 2017).

Stress incontinence is considered the most common type among elderly women affects more than 30 percent of elderly adult women population Worldwide. It is defined as a leakage of urine resulting from weakened perineal muscles combined with sudden increased intra-abdominal pressure (Kocak I, et al., 2014). There are several risk factors associated with stress urinary incontinence include; advanced age, race, higher parity, menopause, hysterectomy, obesity, heavy lifting at work, chronic cough or constipation, family history, dietary habits, lifestyle, and pathological disorders as diabetes (Herzog A R\& Fultz N H., 2016).

With aging there is a decrease in bladder elasticity, which decreases bladder capacity and requires the older adult to void more frequently, and a decrease in the strength of the bladder muscle, likewise, estrogen deficiency in postmenopausal women causes atrophy of the urethral epithelium, resulting in a decreased efficiency of the urethral sphincters (Touhy A., 2013).

Although stress urinary incontinence is not a lifethreatening disease, the loss of bladder control can affect social, psychological, occupational, physical and sexual P a g e | 26 aspects on elderly women (Sirls LT\& Rashid T., 2015). Stress urinary incontinence causes wetness, bad odor, discomfort, skin breakdown, pressure ulcer, and urinary tract infection as physical problems; also, it can be associated with low self-esteem, depression, and social isolation as a result of the shame and embarrassment (Ghafouri A, et al., 2014).

Management of urinary incontinence should start with non-invasive measures because the benefits are associated with low risk and limited expense. Lifestyle modifications, including (smoking cessation, management of constipation, avoidance of excessive fluids, with a reduction in consumption of caffeine, carbonated beverages, diet beverages, frequent intake of small amounts of fluids up to 2 $\mathrm{L}$ a day), timed voiding measures or voiding at intervals that are tailored to each woman (typically every 2 to 3 hours) during the day and pelvic floor muscle exercises instruction. Behavioral therapy was successful greater than $70 \%$ reduction in incontinence episodes (Lukacz, et al., 2017).

Nurses play an important role in improving patients' UI by understanding the experiences of individuals experiencing UI, providing healthcare, and implementing behavioral therapy methods. Managing the incontinent patient is an integral component of nursing practice and can be a challenging and rewarding aspect of nursing care (Arkan, et al., 2018).

\section{Significance of the Study}

Urinary incontinence (UI) considering a common problem, its incidence is twice as high in women as it is in men, and has a significant social, psychological, occupational, sexual, and economic impact, and leading to a substantial decrease in the quality of life (Esparza, et al., 2018). Several studies conducted in Egypt that recorded a high incidence of 
SUI among elderly women living in the community as well as those living in institutions, there are limited studies in Upper Egypt focusing on educational interventions for solving this health problem.

\begin{abstract}
Aim
To evaluate the effect of an educational intervention on reducing stress urinary incontinence episodes among elderly women.
\end{abstract}

\section{Research hypothesis}

- The educational interventions included (Pelvic muscle exercise, Toilet training, and lifestyle modifications will reduce stress urinary incontinence episodes among elderly women.

\section{Research Design:}

Quasi-experimental research design was utilized to fulfill the aim of this study.

\section{Subjects:}

A purposeful sample of fifty elderly women was selected according to the following inclusion criteria.

\section{Inclusion criteria:}

- Females of 60 years and older suffering from stress urinary incontinence.

- Have at least one episode of involuntary urine loss /week.

- Cases of no previous or current urinary incontinence treatment.

\section{Exclusion criteria:}

- Females with any cognitive problems and psychological disorder affecting on alertness and communication.

- Uncontrolled pathological disorders as (spinal injury, stroke, neurogenic bladder)

\section{Setting:}

The study was conducted in Geriatric Nursing Home of Ministry of Social Solidarity and in Geriatric Club of The Red Crescent Society at Minia Governorate, Egypt.

\section{Study Duration:}

The data were collected over a period of nine months starting from June 2018 to February 2019.

\section{Tools of data collection}

\section{Two tools were used for data collection as the following:}

1. Tool I: A Structured interview questionnaire sheet was developed by the investigator after reviewing recent related literature to collect the necessary data from the participants.Adopted from (Yoshida M etal.,2017) \&( Newman D\& Wein A.,2009) It was collected by the researcher at the first interview

\section{It was divided into 2 parts:}

Part I: (Demographic Data): As age, marital status, education, occupation, job before retirement, place of residence, with living condition.
Part II: Medical Profile: Covered history of: Chronic diseases, weight, height and body mass index, obstetric/gynecological, medications, mobility, caffeinated fluid intake, and bowel habits).

2- Tool II: Revised urinary Incontinence Scale (RUIS ) adopted from (sandvic \& et al., 2000).

This scale consisted of 5 questions includes; urine leakage related to feeling of urgency, urine leakage in relation to physical activity (laughing, coughing or sneezing) small amounts of urine leakage, how often did they experience urine leakage?, and how much urine did they lose each time?, People respond to (RUIS) questions by selecting one particular response option from the set of standard response options for each question. These response options were scored by using the numbers presented in brackets to the right of each response option. The RUIS total score is then calculated by adding up a person's score for each question. Adding the score for each of the five questions results in a possible score range of 0 - 16. After that an ISI score calculated by multiplying the scores from questions 4 and 5, resulting in a score range from 0 to 12 , where a 0 score represents no incontinence, scores from 1 to 12 are grouped into the following four severity levels:

$$
1-2=\text { slight } \quad 3-6=\text { moderate } \quad 8-9=\text { severe } 12
$$
$=$ very severe

This tool was used before and after educational intervention and health instructions to evaluate its effect on reducing stress urinary incontinence episodes.

\section{Educational brochure:}

It was formulated by investigator after extensive literature review and revised by experts. It covered the definition of stress urinary incontinence, its causes, and lifestyle modifications in order to control the problem included (limited caffeinated beverages, avoid heavy ligting, controlling chronic constipation etc..), pelvic muscle exercise (Kegel exercise) importance and how to perform it, and instructions given when practicing Kegel exercise, and bladder training technique.

\section{Tools validity:}

The tools were tested for content validity by a jury of five experts in the field of the study and the necessary modifications were done.

\section{Reliability of tools}

To establish reliability, alpha Cronbach's was used to check the stability of the internal consistency of the study instruments which revealed that the tools of the study were reliable as indicated by the value of $(0.87)$.

\section{Pilot Study}

A pilot study was carried out on $10 \%$ (5 women) of the total sample to test feasibility, objectivity, and applicability of the data collection tools. The pilot study sample was included in the actual study sample because no modifications needed.

\section{Ethical Consideration}

Approval was obtained from ethical committee in the Faculty of Nursing, the director of Geriatric Nursing Home of Ministry of Social Solidarity, and the director of Geriatric Club of The Red Crescent Society. Oral consent was obtained 
from the elderly women and explanation about the study was given to them included the aim of the study. Confidentiality and anonymity of each subject were ensured through coding of all data and protecting the obtained data, voluntary participation, and the right to refuse participation in the study were emphasized to subjects.

\section{Procedure}

Data collection for this study was carried out during through the period from June 2018 to February 2019, on the morning, from 9:00 am to 2:00 pm, 2 days per week.. Firstly, the investigator introduced her-self to the women, explained the general purpose of the study $\&$ asked them to give an oral consent for their participation.

The data was collected by the investigator in the first interview which took about 15-20 minutes from each client at the previous mentioned settings, after that the content of the educational brochure introduced for them concerning the behavioral therapy to reduce the episodes of stress urinary incontinence.

\section{Session plan}

Session plan designed according to attention span of the elderly women. Three sessions at three different days were organized for each group of(2to3) women \& each session took about 30- 40 minutes. Session one covered intreusing self and collected interviewing sheet, session two teaching kegel steps and modification of life style and session three educate toilet tranning . The investigator used discussion, demonstration, and re-demonstration as a teaching method. At the end of each session the investigator allowed the woman to ask questions for clarification and gave a conclusion about content, after that the investigator gave them (a brochure) prepared in Arabic language including all items of educational intervention (Pelvic floor muscle exercises, and instructions about preventing constipation and avoidance of lifting heavy objects, and limited caffeinated beverages), and photos to remember them about how to apply these instructions by themselves at their homes.

The investigator followed the adherence of the participants to the educational instruction and to ensure that they are able to perform Kegel exercise as it explained for them accurately by visits or by phone through three times of follow up (after 2 week, 4 weeks, 8 weeks).

The Second tool, (RUIS) was used for participants after 12 weeks of the educational intervention to evaluate the effect of selected behavioral therapy on reducing episodes of stress urinary incontinence for them.

\section{Statistical analysis of data:}

Data were analyzed using the statistical package for social science (SPSS) version 20. Numerical data were expressed as means and SD. Quantitative data were expressed as frequency and percentage. For quantitative data; comparison between two variables were done using t-test, and comparison between more than two variables used ANOVA test paired t-test. Relations between different numerical variables were tested using Pearson correlation. Probability $(\mathrm{P}-$ value) less than 0.05 was considered significant and less than 0.01 was considered highly significant .

\section{Results}

Table (1): Frequency Distribution of the Studied Sample According to their personal Data (N=50).

\begin{tabular}{|c|c|c|}
\hline Characteristics & $(\mathrm{N}=50)$ & $\%$ \\
\hline \multicolumn{3}{|l|}{ Age } \\
\hline - $60-64 y r s$ & 20 & 40 \\
\hline - $65-69 y r s$ & 22 & 44 \\
\hline - $\quad>70 \mathrm{yrs}$ & 8 & 16 \\
\hline \multicolumn{3}{|l|}{ Mean+SD $=68.92+5.39$} \\
\hline \multicolumn{3}{|l|}{ Occupation } \\
\hline - Working & 27 & 54 \\
\hline - $\quad$ House wife & 23 & 46 \\
\hline \multicolumn{3}{|l|}{ Education } \\
\hline - $\quad$ Illiterate & 9 & 18 \\
\hline - $\quad$ Moderate education & 29 & 58 \\
\hline - $\quad$ High school & 12 & 24 \\
\hline \multicolumn{3}{|l|}{ Residence } \\
\hline - $\quad$ Urban & 23 & 46 \\
\hline - $\quad$ Rural & 27 & 54 \\
\hline \multicolumn{3}{|l|}{ Job before retirement } \\
\hline - $\quad$ Heavy work & 27 & 54 \\
\hline - $\quad$ Light work & 23 & 46 \\
\hline \multicolumn{3}{|l|}{ Living condition } \\
\hline - $\quad$ Living with spouse & 7 & 14 \\
\hline - $\quad$ Living alone & 8 & 16 \\
\hline - $\quad$ Living with children & 10 & 20 \\
\hline - $\quad$ Living with extended family & 16 & 32 \\
\hline - $\quad$ Living in geriatric home & 9 & 18 \\
\hline \multicolumn{3}{|l|}{ Marital statues } \\
\hline - $\quad$ Married & 23 & 46 \\
\hline - $\quad$ Divorced & 12 & 24 \\
\hline - $\quad$ Widow & 15 & 30 \\
\hline
\end{tabular}

Table (1) Shows that (44\%) of the studied sample has age 65-69 years old with a mean age of $68.92+5.39$ years old. Also the table displays that $(54 \%, 58 \%$, and 54\%) were working, had moderate education, and living in rural areas respectively .As regards job before retirement, it was found that (54\%) have heavy work, finally $32 \%$ of them were living with the extended family and (46\%) were married. 


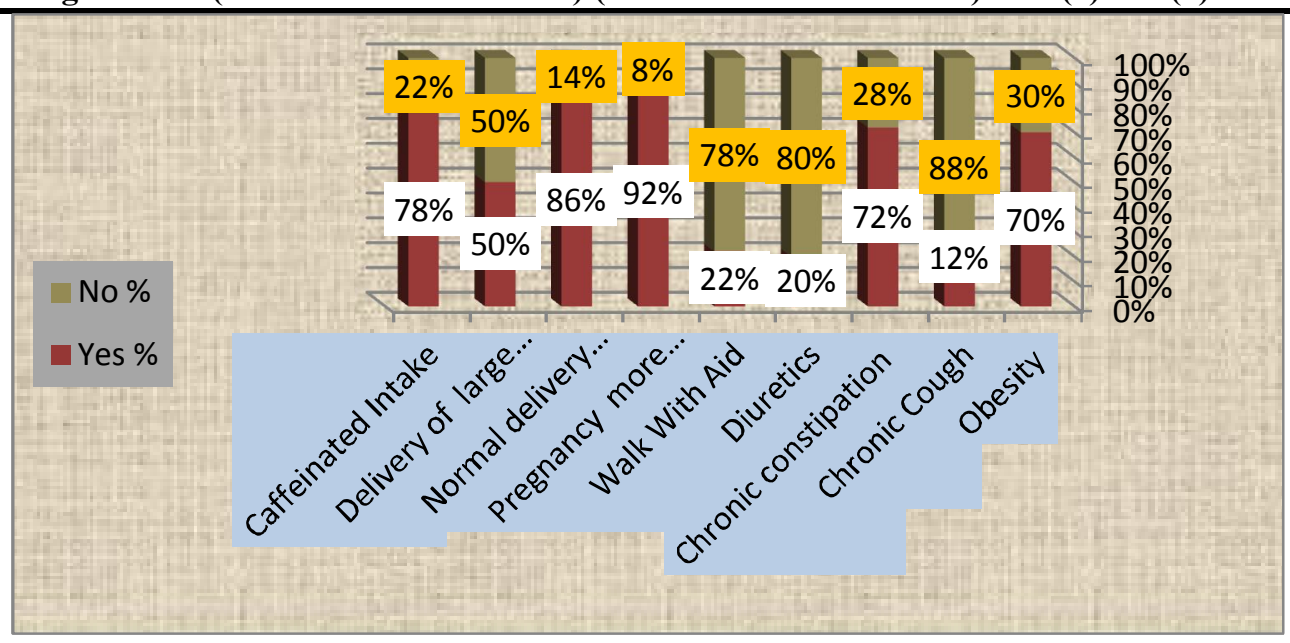

Figure (1): Distribution of the studied sample according to the predisposing factors of stress urinary incontinence ( $\mathrm{N}=50)$.

Figure (1) demonstrates that, the most predisposing factors for stress urinary incontinence founded among the studied sample are (pregnancy more than two times, normal delivery more than two times, caffeine intake, choric constipation, and obesity with percentages of $(92 \%, 86 \%, 78 \%, 72 \% \& 70 \%)$ respectively.

Table (2): Comparison between Urinary Incontinence Severity levels at Pre \& Post educational intervention among the studied Sample $(\mathbf{N}=\mathbf{5 0})$.

\begin{tabular}{|c|c|c|c|c|c|c|c|c|c|c|}
\hline \multirow{3}{*}{ Variable } & \multicolumn{10}{|c|}{ Levels of UI severity } \\
\hline & \multicolumn{2}{|c|}{ Slight } & \multicolumn{2}{|c|}{ Moderate } & \multicolumn{2}{|c|}{ Sever } & \multicolumn{2}{|c|}{ More sever } & \multirow{2}{*}{$\begin{array}{l}\text { Fisher - } \\
\text { exact } \\
\text { test }\end{array}$} & \multirow{2}{*}{$\mathrm{P}$} \\
\hline & $\mathrm{N}$ & $\%$ & $\mathrm{~N}$ & $\%$ & $\mathrm{~N}$ & $\%$ & $\mathrm{~N}$ & $\%$ & & \\
\hline Pre & 4 & 8 & 15 & 30 & 19 & 38 & 12 & 24 & \multirow[b]{2}{*}{38.8} & \multirow[b]{2}{*}{$.000 * *$} \\
\hline Post & 23 & 46 & 13 & 26 & 10 & 20 & 4 & 8 & & \\
\hline
\end{tabular}

Table (2) reflects that, the severity of stress urinary incontinence episodes were declined after the implementation of educational intervention to $8 \%$ compere with $24 \%$ before with highly statistically significant differences $(p=.001)$.

Table (3): Comparison between mean average score of Revised Urinary Incontinence Scale (RUIS) before and the implementation of educational intervention for Studied Sample ( $\mathbf{N}=\mathbf{5 0})$

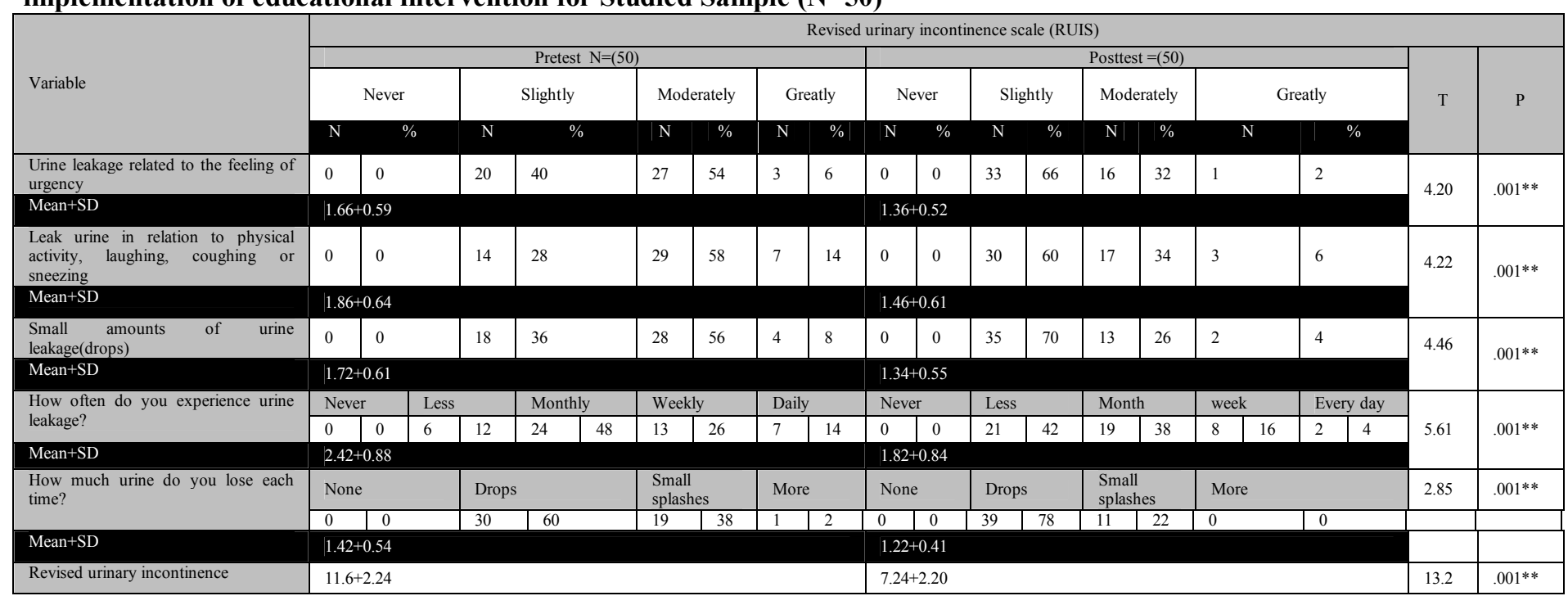

* $\mathrm{p} \leq 0.05$ (significant) T-test: $\mathrm{P}$ - value based on independent sample t-test.

This table : Shows there were a highly statistically significant differences between total mean average score of revised urinary incontinence scale at pre\& post selected behavioral therapy $(\mathrm{p}=.001)$.

Table (4): Relation between Personal Data and the Severity Levels of the Revised Urinary Incontinence Scale (N=50).

\begin{tabular}{|l|l|l|l|l|l|l|l|l|l|l|l|l|}
\hline \multicolumn{1}{|c|}{ Personal data } & \multicolumn{2}{c|}{$\begin{array}{c}\text { Slight } \\
\mathrm{N}=(23)\end{array}$} & \multicolumn{2}{c|}{$\begin{array}{c}\text { Moderate } \\
\mathrm{N}=(13)\end{array}$} & \multicolumn{2}{c|}{$\begin{array}{c}\text { Sever } \\
\mathrm{N}=(10)\end{array}$} & $\begin{array}{c}\text { Very sever } \\
\mathrm{N}=(4)\end{array}$ & $\begin{array}{c}\text { Fisher -exact } \\
(\mathrm{p} \text { value })\end{array}$ \\
\hline
\end{tabular}


Minia Scientific Nursing Journal (Print - ISSN 2537-012X) (Online - ISSN 2785-9797) Vol. (9) No. (1) June 2021

\begin{tabular}{|c|c|c|c|c|c|c|c|c|c|}
\hline \multirow[t]{2}{*}{ Personal data } & \multicolumn{2}{|c|}{$\begin{array}{c}\text { Slight } \\
\mathrm{N}=(23)\end{array}$} & \multicolumn{2}{|c|}{$\begin{array}{c}\text { Moderate } \\
\mathrm{N}=(13)\end{array}$} & \multicolumn{2}{|c|}{$\begin{array}{c}\text { Sever } \\
\mathrm{N}=(10)\end{array}$} & \multicolumn{2}{|c|}{$\begin{array}{c}\text { Very sever } \\
\mathrm{N}=(4)\end{array}$} & $\begin{array}{c}\text { Fisher -exact } \\
\text { ( p value) }\end{array}$ \\
\hline & $\mathrm{N}$ & $\%$ & $\mathrm{~N}$ & $\%$ & $\mathrm{~N}$ & $\%$ & $\mathrm{~N}$ & $\%$ & \\
\hline \multicolumn{10}{|l|}{ Marital statues } \\
\hline - $\quad$ Married & 12 & 24 & 4 & 8 & 6 & 12 & 1 & 2 & \multirow{3}{*}{ 4.45(.635)NS } \\
\hline - $\quad$ Divorced & 5 & 10 & 5 & 10 & 1 & 2 & 1 & 2 & \\
\hline - $\quad$ Widow & 6 & 12 & 4 & 8 & 3 & 6 & 2 & 4 & \\
\hline \multicolumn{10}{|l|}{ Education } \\
\hline - $\quad$ Illiterate & 0 & 0 & 3 & 6 & 5 & 10 & 1 & 2 & \multirow{3}{*}{$\begin{array}{l}29.588 \\
\left(.001^{* *}\right)\end{array}$} \\
\hline - $\quad$ Middle education & 11 & 22 & 10 & 20 & 5 & 10 & 3 & 6 & \\
\hline - $\quad$ High school & 12 & 24 & 0 & 0 & 0 & 0 & 0 & 0 & \\
\hline \multicolumn{10}{|l|}{ Occupation } \\
\hline - Work & 0 & 0 & 13 & 26 & 10 & 20 & 4 & 8 & \multirow{2}{*}{$\begin{array}{l}57.814 \\
(.001 * *)\end{array}$} \\
\hline - $\quad$ House wife & 23 & 46 & 0 & 0 & 0 & 0 & 0 & 0 & \\
\hline \multicolumn{10}{|l|}{ Job before retirement } \\
\hline - $\quad$ Heavy & 0 & 0 & 13 & 26 & 10 & 20 & 4 & 8 & \multirow{2}{*}{$\begin{array}{l}57.814 \\
\left(.001^{* *}\right)\end{array}$} \\
\hline - $\quad$ Not heavy & 23 & 46 & 0 & 0 & 0 & 0 & 1 & 0 & \\
\hline \multicolumn{10}{|l|}{ Location } \\
\hline - $\quad$ Urban & 23 & 46 & 0 & 0 & 0 & 0 & 0 & 0 & \multirow{2}{*}{$\begin{array}{l}57.814 \\
(.001 * *)\end{array}$} \\
\hline - $\quad$ Rural & 0 & 0 & 13 & 26 & 10 & 20 & 4 & 8 & \\
\hline \multicolumn{10}{|l|}{ Living condition } \\
\hline - $\quad$ Living with spouse & 5 & 10 & 0 & 0 & 2 & 4 & 0 & 0 & \multirow{5}{*}{$10.4(.557) \mathrm{Ns}$} \\
\hline - $\quad$ Living alone & 4 & 8 & 2 & 4 & 1 & 2 & 1 & 2 & \\
\hline - $\quad$ Living with children & 3 & 6 & 3 & 6 & 4 & 8 & 0 & 0 & \\
\hline - $\quad$ Living with extended family & 8 & 16 & 5 & 10 & 2 & 4 & 1 & 2 & \\
\hline - $\quad$ Living with nursing home & 3 & 6 & 3 & 6 & 1 & 2 & 2 & 4 & \\
\hline
\end{tabular}

Table (4) shows that, there were highly statistically significant differences between (age, education, occupation, job before retirement, and location) and theRevised Urinary Incontinence Scale (RUIS) score after nursing intervention , in which severity of stress urinary incontinence episodes declines among age group (60:64)years, high education, not have heavy work, and those living in urban areas $(p=.001)$ during posttest.

\section{Discussion}

Discussion of the demographic characteristics of the Studied Sample.

Concerning the age of the studied sample, it was found that nearly half of the sample were aged 65-69 years old with a mean age of $(68.92+5.39)$. From researcher point of view aging process associated with many changes in the urinary tract may lead to weakness of bladder muscle strength, and reduce bladder capacity. This finding was similar to findings of El Badawy et al., (2013) who conducted a study entitled "Health Education Intervention for Controlling of Stress Urinary Incontinence among Elderly Women at Zagazig City" and found that the more than half of elderly women with stress urinary incontinence aged 65 years. Also, it was in the same line with Samantha, (2016) who found that the mean age of the studied sample were more than 60 years. However, this finding disagreed with Wilda \& Andriani, (2018) they revealed that more than half of the studied sample age ranged between 70 to 79 years.

Regarding the educational level, the current study findings showed that more than half of the studied sample has a moderate level of education, this can be act as a reason that elderly women with (UI) don't think that they are in need for medical advice. These outcomes were matching with Altman et al., (2017) who showed that most participants were illiterate. In relation to the residence, the present study findings reported that about half of the sample was living in rural areas. From the researcher point of view, the women from the rural areas might be working in the farm, and carry heavy object, and delivered more children because of culture in rural area encourages increased number of children.

This finding was in agreement with $\mathrm{Ng}$ et al., (2020) they pointed that highest percentage of stress urinary incontinence among women from a rural area. While disagree with $P$ a g e $\mid 30$
Engberg, (2018) who reported that the majority of the studied group ere from urban area.

As regard to job before retirement, it founds that more than half of studied sample demonstrate heavy work. From researcher point of view that heavy works and heavy lifting increase the risk for (SUI). This finding was supported by Nygaard \& Shaw, (2016) who stated that high physical activity can effect and increase of (SUI).

Discussion of the lifestyle and the predisposing factors that reported by the studied sample.

The current finings demonstrated that the most predisposing factors for stress urinary incontinence founded among the studied sample are (pregnancy more than two times, vaginal deliveries more than two times, caffeine intake, choric constipation, and obesity.

Theses was similar to findings of Vahdatpour et al., (2015) who reported that chronic constipation were the most risk factors for stress urinary incontinence. Moreover, Khullar et al., (2014) reported that UI was significantly associated with high BMI, vaginal delivery. Additionally is matching with El Badawy et al., (2013) who demonstrated increased episodes of (SUI) among women who drink caffeinated beverages and discussed as such fluids can irritate the bladder. While it was opposite to Mohammed et al., (2018) who illustrated that the greatest episode of urinary dribbling was linked to coughing, laughing or sneezing.

Discussion for the effect of the educational intervention on stress urinary incontinence episodes among the studied sample.

The current results reflected a significant increase in the mean average score of revised urinary incontinence scale after the implementation of selected behavioral therapy versus to before, and the severity of stress urinary incontinence Asmaa E., et al 
episodes were declined with a highly statistical significant differenceat pre and post-tests. These results were supported by El Badawyet al., (2013) who reported a decreased of mean of wetting underwear among studied group after implementation of educational program, comparing with before intervention program. This can be discussed as the Kegel and toilet training increase the function capacity of the urinary bladder, and consequently leads to that improvement. Also, these finding are incongruent with Marques et al., (2018), who mentioned that performing Kegel's exercise regularly for 4-6 weeks helps strengthening the pelvic floor muscle and controlled UI.

Discussion of the relation between personal data and the severity levels of the revised urinary incontinence scale among the studied sample:

The finding of this study showed that (age, education, occupation, job before retirement and location) are significantly affect the severity of urinary incontinence at post-test, in which severity of stress urinary incontinence episodes declined among those of age $(60: 64)$ years, high education, not have heavy work and those living in urban areas. These results were on the same line with Agarwal and Agarwal, (2017), who stated that there was significant association of increasing age and episodes of urinary incontinency. Also these outcomes were supported by El Badawy et al., (2013) who stated that there was a significant relation between the prevalence of (SUI) and unemployed female, and agrees with Join, (2012) stated that there was a significant relation between the prevalence of stress urinary incontinence and illiteracy. On other hand this result was opposite with Weber and Kelley, (2012) who stated that stress urinary incontinence (SUI) is common problem in all age groups among Americans' women.

\section{Conclusions:}

Educational interventions included pelvic floor muscle exercise and lifestyle modifications were effective in reducing stress urinary incontinence episodes among elderly women.

\section{Recommendations:}

1) A continuous education and training should be offered on a regular basis for elderly women in different health care settings, nursing homes and geriatric social club to reduce episodes of stress urinary incontinence.

2) An educational booklet containing information about age-related changes, lifestyle modifications, importance of medical follow up, and practice of pelvic floor exercises should be available in geriatric homes and geriatric clubs.

3) Replication of the current study on larger probability sample and on other health care settings.

\section{References}

(1) Agarwal, B. K., \& Agarwal, N. (2017). Urinary incontinence: prevalence, risk factors, impact on quality of life and treatment seeking behaviour among middle aged women. International Surgery Journal, 4(6), 1953-1958.

(2) Altman, D., Cartwright, R., Lapitan, M. C., Milsom, I., Nelson, R., Sjöström, S., \& Tikkinen, K. A. (2017). Epidemiology of urinary incontinence (UI) and other lower urinary tract symptoms (LUTS), pelvic organ prolapse (POP) and anal incontinence (AI). In Incontinence: 6th
International Consultation on Incontinence, Tokyo, September 2016 (pp. 1-141). International Continence Society.

(3) El Badawy, R. E. S., Ali, S. A., Abo El-Seoud, A. R., \& Abd Allah, E. S. (2013). Health Education Intervention for Controlling of Stress Urinary Incontinence among Elderly Women at Zagazig City. Zagazig Nursing Journal, 9(2), 49-65.

(4) Engberg, S. (2018). Management of Urinary Incontinence in the Presence of Fecal Incontinence. In Management of Fecal Incontinence for the Advanced Practice Nurse (pp. 291-305). Springer, Cham.

(5) Ghafouri A, Abdullah R, Alroubi I, Alrayashi M, Ahmed A.(2014) Urinary incontinence in Qatar: A study of the prevalence, risk factors and impact on quality of life. Arab J Urol[Internet],12(4): 269-74. Available from : https://www.ncbi.nlm.nih.gov/pmc/articles/PMC4435520/p df/main.pdf

(6) Herzog A R, Fultz N H. urinary incontinence in community dwelling elderly populations.(2016). J Am Geriatr Soc [Internet],38(3):273-281. Available from https://www.ncbi.nlm.nih.gov/pubmed/?term urinary incontinence in community dwelling elderly populations. J Am Geriatr Soc. 2016 3B38(3) 3A273 E2 8093281.

(7) Join.M. (2012). Medscape Education Neurology \& Neurosurgery. 2012; located at website: http://ww.medscape.org/viewarticle.D ate of access $/ 16 / 6 / 2012$

(8) Khullar, V., Sexton, C. C., Thompson, C. L., Milsom, I., Bitoun, C. E., \& Coyne, K. S. (2014). The relationship between BMI and urinary incontinence subgroups: results from EpiLUTS. Neurourology and urodynamics, 33(4), 392-399.

(9) Kluwer W, Williams L .(2011) Nursing Guide to Expert Elder Care. Urinary incontinence in older adults.

(10) Kocak I, Okyay P, Dundar M, Erol H, Beser E.(2014). Female urinary incontinence in the west of Turkey: prevalence, risk factors and impact on quality of life. Eur Urol [Internet], 48:634-41.

(11) Marques A., Lynn Stothers, \& Andrew Macnab. (2018). The status of pelvic floor muscle training for women. Can Urol Assoc J. 2018; 4(6): 419-424.

(12) Mohamed, H. G., Hafez, S. K., \& Basyouni, N. R. (2018). Effect of Pelvic Floor Muscle Strengthening-Kegel's Exercise-on Severity of Stress Urinary Incontinence and Quality of Life Among Women. International Journal of Novel Research in Healthcare and Nursing Vol. 5, Issue 3, pp: (421-438), Month: September - December 2018, Available at: www.noveltyjournals

(13) National Association for Continence.(2017). Women stress urinary incontinence [Internet] 1-800-252-3337.Available from: https://www.nafc.org/womens-stress-urinaryincontinence

(14) Newman D\& Wein A(2009) . Managing and Treating Urinary Incontinence, 2nd Ed.

(15) Ng, K. L., Ng, K. R., Thu, W. P. P., Kramer, M. S., Logan, S., \& Yong, E. L. (2020). Risk factors and prevalence of urinary incontinence in mid-life Singaporean women: the integrated Women's health program. International urogynecology journal, 31(9), 1829-1837.

(16) Nygaard, I. E., \& Shaw, J. M. (2016). Physical activity and the pelvic floor. American journal of obstetrics and gynecology, 214(2), 164-171.

(17) Samantha. Y.Y. (2016). Effectiveness of pelvic floor muscle training on women with stress urinary incontinence. The University of Hong Kong. Degree of Master of Nursing.

(18) Sirls LT, Rashid T.(2015). Consequences of urinary incontinence. Geriatr Nephrol Urol[Internet],9:87-99. 
(19) Touhy A.(2013). Textbook of Gerontological Nursing \&Healthy aging. Aging changes affecting renal system, $p$ 45-47.

(20) Vahdatpour, B., Zargham, M., Chatraei, M., Bahrami, F., \& Alizadeh, F. (2015). Potential risk factors associated with stress urinary incontinence among Iranian women. Advanced biomedical research, 4.

(21) Wahyudi, A. S., Sulastri, S. K., \& Jadmiko, A. W. (2017). Pengaruh Latihan Senam Kegel Terhadap Frekuensi Berkemih Pada Lansia (Doctoral dissertation, Universitas Muhammadiyah Surakarta).

(22) Weber J \& Kelley J.H.(2012). Health assessment in nursing, 5th ed., United State of America, Lippincott Williams \&Wilkins CO., 2012; PP: 764-765
(23) Wilda, L. O., \& Andriani, N. D. (2018). The Influence of Kegel Exercise on Elderly Patients with Urinary Incontinence in Technical Implementation Unit of Social Service Tresna Werdha Jombang. Nurse and Health: Jurnal Keperawatan, 7(2), 106-112.

(24) Williams L. (2011). Nursing guide to expert elder care. Common urological disorders in older adults. 560-576.

(25) Yoshida M, Homma Y, Inadome A. Age-related changes in cholinergic and purinergic neurotransmission in human isolated bladder smooth muscles. Experimental gerontology. 2016 Jan;36(1):99-109. [PubMed] 